\title{
Elma Islahında ve Çeşit Yönetiminde Yenilikçi Eğilimler
}

\author{
A. Nilgün ATAY ${ }^{1 *}$, Ersin ATAY ${ }^{2}$ \\ ${ }^{1}$ Meyvecilik Araştırma Enstitüsü, Eğirdir/Isparta, Türkiye \\ ${ }^{2}$ Mehmet Akif Ersoy Üniversitesi, Burdur Gıda Tarım ve Hayvancılık Meslek Yüksekokulu, Bitkisel ve \\ Hayvansal Üretim Bölümü, Bahçe Tarımı Programı, Burdur, Türkiye \\ *sorumlu yazar: nilguntuncer@hotmail.com, Tel: +90 (246) 3132420/192
}

Özet: Son yıllarda dünyada çeşit tanıtımı ve yönetimi oldukça değişmiştir. Meyve endüstrisinde giderek artan rekabet yeni çeşitlerin potansiyel değerini almasını ve korumasını zorlaştırmaktadır. Bu nedenle çalışmada, elma ıslahındaki ilerlemeler, sektörün motivasyonunu etkileyen faktörler, 1slahçı hakları, ticari markalar gibi konulara ışık tutmak ve bunların elma endüstrisini nasıl şekillendirdiğini açıklamak amaçlanmıştır. Sürekli büyüyen bir sektörde yeni çeşitlerin başarı sağlayabilmesi için dikkate alınması gereken birçok faktör vardır. Sektörün ihtiyaçlarını ve tüketicilerin istediklerini anlamak ve bu ikisi arasındaki dengeyi kurmak hayati önem taşımaktadır. Yeni çeșitlerin pazara girmeyi başarabilmeleri için mutlaka sosyal, ekonomik ve ekolojik açıdan üstünlüklerinin olması gerekmektedir. Gelinen noktada yeni çeşitlerin yönetiminde küresel yönetim ve markalaşma kaçınılmazdır. Dolayısıyla ıslah programları küresel sorunları göz önünde tutarak etkin ve verimli ticarileştirme planlarına hızla uyum sağlamak durumundadır. Bu çalışmanın elma sslah programlarında etkinliği ve bilinci arttırarak, potansiyel risklerin dengelenmesinde faydalı olabileceği düşünülmektedir.

Anahtar kelimeler: Bitki ıslahçı hakları, Ticarileştirme, Meyve kalitesi, Melezleme

\section{Innovational Trends in Apple Breeding and Cultivar Management}

Abstract: In recent years, the release and management of cultivars have changed considerably in the world. Increasing competition in the fruit industry makes harder of the potential and protect of new cultivar. Thus, this paper seeks to describe the advancement of apple breeding, the factors influenced the motivations of the industry, plant breeders' rights, trademarks, and understand how they have shaped the apple industry today. In an industry that is constantly expanding, there are many factors that need to be taken into consideration in order to succeed of new cultivars. It is vital to understand the needs of the sector and what consumers want and to establish a balance between them. The new cultivars must have social, economic and ecological advantages to achieve entry into the market. At now global management and branding are inevitable in the management of new cultivars. Therefore, breeding programs must be quickly adapted to the efficient and effective commercialization programs taking into account global issues. This study may be useful in balancing potential risks by increasing efficiency and awareness in apple breeding programs.

Key words: Plant breeders’ rights, Commercialization, Fruit quality, Crosssing

\section{Giriș}

Elma (Malus domestica Borkh.) birçok meyvenin aksine tüketiciler tarafından çeşit bazında kolaylıkla tanınan ve aranan bir meyve türüdür. Bu nedenle çeşitler elmanın pazarlanmasında önemli bir unsurdur (Luby ve Bedford 2015). Meyve endüstrisindeki gelişmeler sayesinde özellikle son 30-35 yılda elmada çeşit sayısı oldukça artmış ve dinamik bir yapı kazanmıştır.

Günümüzde elma çeşitleri, diğer birçok 1lıman iklim meyve türünde olduğu gibi modern 1slah programlarının bir sonucu olarak uzun ıslah ve ticarileştirilme süreci sonrasında ortaya çıkmaktadır (Atay ve ark. 2016a; Brown ve Maloney 2015; Kumar ve ark. 2014; Evans 2013; Hancock ve ark. 2008). Klasik bir elma çeşit geliștirme ve ticarileştirme programının aşamaları Şekil 1'de gösterilmiştir. 


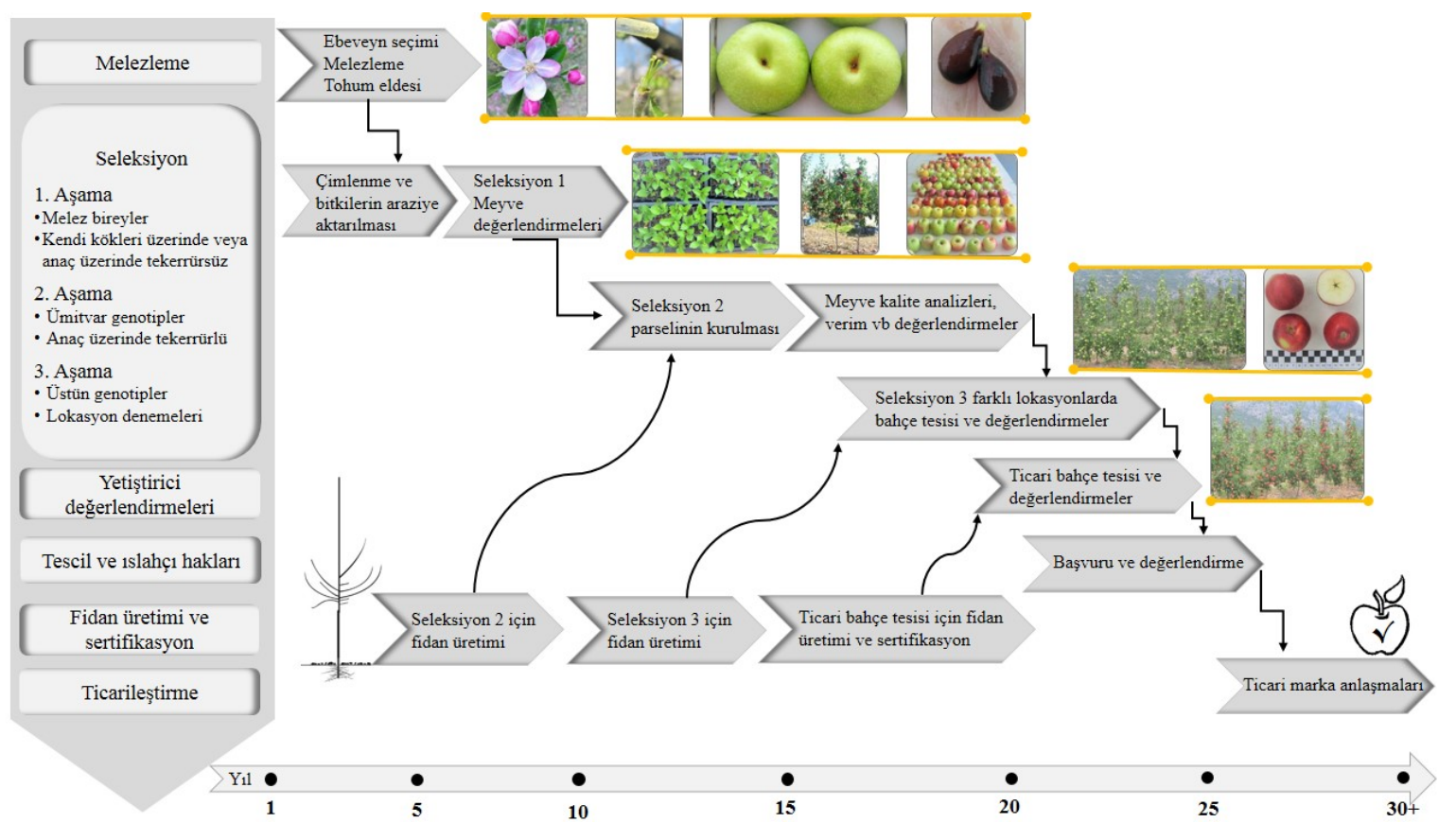

Şekil 1. Klasik bir elma çeşit ıslah programının temel aşamaları, faaliyetler ve zaman çizelgesi (Oklar ve çizgiler bitki materyalinin hareketini belirtir).

Ebeveynlerin belirlenmesi ile başlayan bu süreç birbirinden bağımlı/bağımsız birçok uzun ve yoğun aşamadan oluşmaktadır. Islah çalışmalarında kullanılan tohumlar, genellikle kontrollü melezlemeler sonucu elde edilmektedir. Katlama ve çimlendirmeden sonra bitkiler ekstra bir anaç ve aşı gideri olmaması için genellikle kendi kökleri üzerinde araziye aktarılmaktadır. Elmanın 3 ile 8 yıl arasında değişen uzun bir gençlik kısırlığ periyodu vardır (Webster 2005). Meyvesiz geçen bu periyot süresince hastalıklara dayanım açısından taramalar, vejetatif gelişime ya da belirteçlere bağlı olarak yapılan değerlendirmeler popülasyonu azaltmak amacıyla kullanılabilmektedir (Pereira-Lorenzo ve ark. 2009; Hancock ve ark. 2008; Schmidt ve van de Weg 2005).

İlk meyveler görüldükten sonra, her programın kendi amaçları ve önem derecelerine göre bazı değişikler söz konusu olsa da, seleksiyonlar genellikle üç aşamalı olarak yapılmaktadır. İlk aşamada görünüm ve yeme kalitesi gibi daha çok tüketici özellikleri göz önünde tutulmaktadır. Yapılan incelemelerde ümitvar olarak seçilen genotipler ile ikinci aşamaya geçilmektedir. Bu aşamada genotipler M.9 gibi standart anaçlar üzerinde ticari çeşitler ile bir arada genellikle 4-6 ağaç olacak şekilde denenmektedir. Ayrıca bu aşamada tüketici tarafindan aranılan özelliklerin yanısıra verim, ağaç formu ve depo ömrü gibi ticari özellikler de seleksiyonda dikkate alınmaktadır. Üçüncü aşama ise çoğunlukla çevresel farklılıkların incelendiği, genotip X çevre interaksiyonunun değerlendirildiği bir aşamadır. Neticede elmanın albenisi, tüketiciler tarafından ne derece tercih edileceği ve bölgedeki ticari kabul edilebilirliği bütün bu aşamalardan sonra belirlenmektedir. Ayrıca çeşit tescili, 1slahçı hakk1, ticarileştirme ve her aşamada tekrar fidan üretimi göz önünde tutulursa 5-10 yıllık bir gecikme her zaman olasıdır (Macduff ve Macduff 2016; Luby ve Bedford 2015). Dolayısıyla bu programlar tüketiciler için yeterli meyve hacmini de ele alınca 30 yılı kolaylıkla aşabilmektedir. Bu kadar uzun vadeli yatırımlar da bir çeşidin başarılı olması gerektiği anlamına gelmektedir.

Nitekim gelinen noktada meyve 1slahı, sadece sözde değil, pratikte de yeni bir döneme girmiştir. Önümüzdeki süreçte her yeni çeşidin başarı şansının daha zorlayıcı olması muhtemeldir. Bu nedenle çalışmada elma ıslahındaki ilerlemeler, sektörün motivasyonunu nelerin etkilediği, ıslahçı hakları, ticari markalar gibi konulara 1şık tutmak ve bunların elma endüstrisini nasıl şekillendirdiğini anlamak amaçlanmıştır.

\section{Neden Yeni Çeşit?}

Dünyada ticari açıdan önemli elma çeşidi sayısı 10-12 civarında olmasına rağmen toplamda çeşit sayısının 6000'in çok daha üzerinde olduğu bildirilmektedir (Anonim 2015; O’Rourke 2003). Bunların birçoğu tesadüf çögürü, bazıları ise kontrollü melezlemeler sonucu elde edilmiştir. Ayrıca her yıl profesyonel ve amatör 1slahçılar tarafından bu sayıya sürekli yenileri eklenmektedir (Atay ve ark. 2016b; Brown ve Maloney 2013).

$\mathrm{Bu}$ durumda; neden binlercesi halihazırda varken yeni çeşitlerin geliştirilmeye devam edildiği veya dünya çapında çok sayıda başarılı ıslah programı yürütülmekte iken neden yeni programlar başlatıldığı gibi bazı sorular 
kaçınılmazdır. Bunlar aslında oldukça makul sorulardır, ancak hayatın her alanı için benzer sorular sorulabilmektedir (Macduff ve Macduff 2016). Nitekim insanlar sayısız örneğe sahip olsalar bile doğası gereği hayatları boyunca yeni, farklı veya daha iyi bir şeyler üretmek istemektedirler. Bu durum hiç kuşkusuz meyve çeşitleri içinde geçerlidir. Üreticiler, tüketiciler ve bu işin ticaretini yapan herkes daha iyi kalitede ürüne her zaman ihtiyaç duyabilmektedir.

Bu konuyu ülkeler perspektifi üzerinden ele alacak olursak; özellikle Türkiye gibi önemli üretim kapasitesine sahip ülkelerde ıslah çalışmaları göz ardı edilmemelidir. Bu çalışmalar özellikle ülkelerin elma kültürünü sürdürülebilmesi adına çok önemlidir. Nitekim yeni çeşitlerin geliştirilmesi, stratejik, kültürel veya ticari nedenlerden biri veya hepsi için yapılabilmektedir (Macduff ve Macduff 2016). Orijini ülkelerin kendine ait yeni çeşitler, hiç kuşkusuz meyvecilik sektörünü çeşitlendirip destekleyecektir.

Diğer bir açıdan ise yeni çeşitler, küresel pazarda yetiştiricilere, pazarlamacılara ve perakendecilere önemli bir fark noktası ve rekabet avantajı sunabilmektedir (Clark ve Jondle 2008; Jondle ve ark. 2015). Bu durum yeni çeşitler için oldukça iyi bir firsattır. Dünya elma ticaretine baktığımızda da özellikle son yıllarda yeni çeşitlerin payının gittikçe arttığı görülmektedir. Modern meyvecilikte söz sahibi Yeni Zelanda, Avusturalya, Fransa ve İtalya gibi ülkelerde yeni çeşitlerin elma üretimindeki payı \%10-30 arasında değişmektedir (Anonim 2015). Türkiye gibi bazı ülkelerde ise yeni elma çeşitlerinin üretimdeki payı henüz çok sınırlı olsa da önümüzdeki yıllarda özellikle eski bahçelerin düzenli olarak yenilenmesi sürecinde koşulların yeniden gözden geçirilmesi kaçınılmazdır.

Sürekli genişleyen bir sektörde yeni çeşitlerin başarı sağlayabilmesi için dikkate alınması gereken birçok faktör vardır. Bir şeyin ‘yeni' olması başarılı olduğu anlamına gelmemektedir. Burada söz konusu olan ne olursa olsun yeni çeşitler elde etmek değil ekonomik bakımdan değerli olanları yetiştirmektir. Plansız bir 'çeşit yapıcılığının' bilinçli bir sslahla ilgisinin bulunmadığı çok açıktır (Özbek 1971). Sektörün ihtiyaç duyduğu şeyleri ve tüketicilerin ne istediklerini anlamak ve bu ikisi arasındaki dengeyi kurmak hayati önem taşımaktadır (Volz 2011). Genel olarak, iklim faktörleri, irilik ve kalite parametreleri, belirli kültürel uygulamalar, hastalıklara dayanım ve hedef market ya da pazarlama stratejileri bir çeşidin kabul edilmesinde etkili faktörler olarak ifade edilmektedir (Weber 2017; Byrne 2012; Luby 2011; Anonim 2011). Ancak özellikle hedef market ya da pazarlama stratejisi bu alandaki gelişmeler sayesinde en önemli faktör olarak karşımıza çıkmakta ve diğer bütün unsurları değiştirebilmektedir. Unutulmamalıdır ki markalaşma sürecinde yeni çeşitlerin 1slahı sadece bir başlangıçtır.

\section{Çeşit Yönetimi}

Meyve endüstrisinde artan çeşit sayısı, değişen rekabet ve pazar koşulları beraberinde 'çeşit yönetimi' kavramını getirmiştir. 1960'lı yıllara kadar dünyada meyve 1slah programları neredeyse tamamen kamu tarafindan finansa edilmiştir (Atay ve ark. 2010). Dolayısıyla meyve çeşitlerinde hiçbir kısıtlama olmaksızın serbest dolaşım söz konusu olmuştur. Ancak bu tarihten itibaren kamunun meyve 1slah programlarına ayırdığı bütçe giderek azalmış ve hatta birçoğu feshedilmiştir (Luby ve Bedford 2015). 1970’lerden itibaren geriye kalan kamu sektör programları yeni çeşitlerde bitki sslahçı hakları ya da ABD'de olduğu gibi bitki patenti gibi yasal korumaları gündeme getirmiştir (Clark ve Jondle 2008; Byrne 2012). Bu yaklaşımlar ile ülkelere bağlı olarak 20-30 yıl süreyle yetkisiz çoğaltmaya karşı yasal koruma sağlamayı hedeflemişlerdir (Jondle ve ark. 2015). Bu kapsamda sadece yasal olarak elde edildiği takdirde çeşitlerin ıslah çalışmalarında veya araştırma amaçlı kullanımına izin verilmektedir.

20. yüzyılın sonlarında üretim, depolama ve nakliye teknolojisindeki gelişmeler tüketicilere yıl boyunca meyve tedarik edilmesini sağlamıştır (El-Ramady ve ark. 2015; Watkins 2003). Örneğin sonbaharda hasat edilen elma uzun süre soğukta depolanarak veya ek olarak Şili, Yeni Zelanda gibi güney yarımküre ülkelerinden ithal edilerek bütün yıl boyunca pazarlanabilmektedir. Bu küresel elma ticareti hareketleri, çeşitlerin fidanlıklar, üreticiler ve pazarlamacılar tarafından yaygın bir şekilde tanınmasına yol açmış ve özel sektörün 1slah çalışmalarındaki payını arttırmıştır (Byrne 2012; Lespinasse 2009; Heisey ve ark. 2001). Kamudaki 1slah programlarının giderek azalması da bu süreci hızlandırmıştır. Nitekim özel sektörün bu ilgisi meyve çeşitlerinin ticarileştirilmesini etkileyen farklı bir eğilim ortaya çıkarmıştır.

Özel sektör ıslah programları, çeşitlerini ıslahçı haklarının yanı sıra ticari markalar ile korumaya başlamıştır. Ticari markalar, yönetim stratejilerinde bazı değişiklikler görülse bile genellikle temelde bir veya birkaç üreticiye veya pazarlamacıya bir veya daha fazla ülkede meyve üretmek ve pazarlamak için bir markanın kullanım hakkını ifade etmektedir (Jondle ve ark. 2015). Bu sistem temelde sınırlı üretim, sınırlı pazar, özel kültürel gereksinimler ve sözleşmeli düzenlemeler gibi unsurları içermektedir (Clark ve ark. 2012). Böylece ürünün miktarının, 
kalitesinin ve fiyatının korunduğu ifade edilmektedir. Ticari markaların korunma süresi, gerekli şartlar yerine getirildiği takdirde istenildiği kadar uzatılabilmekte veya yenilenebilmektedir (Luby ve Bedford 2015; Jondle ve ark. 2015). Buna karşılık, çeşitlerin ticari markalarla korunması üretilen her bir fidan için ve bazen her meyve için telif hakkı ödenmesini gerektirmektedir (Clark ve Jondle 2008). Bu şekilde çok sıkı kontrollü çeşitler, elma endüstrisinde 'kulüp çeşitler' olarak ifade edilmektedir.

Kulüp çeşitlerde fidancılar, üreticiler veya pazarlamacılar sözleşme taahhütleri karşılığında çeşidin özel erişim hakkına sahip olabilmektedir (Luby ve Bedford 2015). Dolayısıyla belirli kalite kriterlerini karşılamak için bahçe kuruluşundan meyve pazarlamasına kadar geçen süreçte bazı yükümlülükleri yerine getirmek zorundadırlar (Clark ve ark. 2012). Nitekim piyasadaki meyve kalitesinin sürekli olarak yüksek tutulması, çeşidin başarısını ve dolayısıyla ticari ömrünü doğrudan etkilemektedir. Komplike bir altyapı sistemine ihtiyaç duyan bu kulüp çeşitler için markayı destekleyen stratejiler geliştirilmiş ve böylece meyve endüstrisine farklı bakış açıları sunulmuştur.

Sadece 1slahçı hakları ile korunan çeşitlerde, 20-30 yıl olarak belirtilen koruma döneminin çoğu bir tüketici bilinci kazanamadan tükenmektedir (Luby ve Bedford 2015). İstenen pazar payı ve hacmine ulaşılamadığı için çeşidin ticarileştirme aşaması çok yavaş ilerlemektedir. Nitekim pazarlama ve tanıtım olmaksızın tüketicilerin yeni bir çeşidin farkına varma olasılığ risk alıp farklı bir çeşide eğilim göstermeleri genellikle zordur. Ayrıca genellikle çeşit sahipleri, çeşitlerini tüketicilere pazarlamak için gereken uzmanlık veya kaynağa sahip değildirler. Üretim ve lojistik kaynaklarını kontrol altında tutmaları da oldukça zor olabilmektedir. Dolayısıyla olası riskler göz önüne alınırsa yeni bir çeşidi üretmek, pazarlamak ve teşvik edebilmek için sağlam bir kontrolün oluşturulması zorunlu görülmektedir. Ticari marka ile desteklenen kulüp çeşitler ise güçlü bir işbirliği ve destekle sunulduğu için hem tüketicilere hem de üreticilere önemli teşvikler sunabilmektedir (Wilton 2017; Anonim 2015). Ayrıca kulüp çeşitlerde sadece belirli sayıda tanımlanmış yetiştirici ve pazarlamacı söz konusu olduğu için çeşitlerin takibi daha kolay yapilabilmektedir.

Diğer bir konu ise bir çeşidin daha iyi renk ve görünüme veya farklı büyüme karakterine sahip mutasyonları üreticiler/fidancılar tarafından düzenli olarak aranmakta ya da tesadüfen keşfedilmektedir (Atay ve ark. 2018). Bu tarz mutasyonlar UPOV'a imza atan ülkelerde ‘orjinalinden türetilen' çeşit olarak kabul edilmektedir (Jondle ve ark. 2015) ve ticarileştirilmesi orijinal çeşidin sahibi tarafından yapılmaktadır. Ancak bazı ülkelerde ve bazı durumlarda, bu çeşitler orijinal çeşit sahibinin izni olmaksızın ticari hale getirilebilmektedir. Çeşit sahibi bazı sözleşmeler yoluyla mutantları kontrol edebilmekte fakat bu tür bir düzenleme ciddi bir resmi prosedür gerektirdiği için pratikte yaygın olarak uygulanmamaktadır. Kulüp çeşitlerdeki sınırlı sayıdaki ortaklık ve yapılan sözleşmeler ile mutantların korunması da sağlanabilmektedir (Luby ve Bedford 2015).

Günümüzde kontrollü olarak yetiştirilen kulüp çeşitleri sayısı gittikçe artmaktadır. 'Cripps Pink cv./Pink Lady ${ }^{\circledR}$, bu alanda ilk model olup çeşit yönetiminde yepyeni bir yol göstermiş ve sonraki birçok çeşit içinde teşvik edici rol oynamıştır (Cripps ve ark. 1993; Anoinm 2015). Geniş bir pazar potansiyeline sahip olan Pink Lady ${ }^{\circledR}$ uluslararası gruplar tarafından yönetilmekte ve üretim miktarı ve alanı daha denetimli olarak kontrol edilmektedir. Scifresh Cv./Jazz ${ }^{\circledR}$ elmasının pazarlama stratejisi de buna iyi bir örnektir. Yine Ambrosia ${ }^{\mathrm{T}}$, Cameo $^{\circledR}$, Envy $^{\mathrm{TM}}$, Evelina $^{\circledR}$, Honeycrunch $^{\circledR}$, Kanzi $^{\circledR}, \mathrm{Kiku}^{\circledR}$, Lady Alice ${ }^{\circledR}$, Opal $^{\circledR}$, Rockit $^{\circledR}$, Smitten $^{\mathrm{TM}}$, SweetTango $^{\mathrm{TM}}$ kulüp çeşitlerden başarı sağlayanlar arasındadır (Wilton 2017; Brown ve Maloney. 2009). Bütün bu markalar çeşitlerini küresel anlamda test edip koruyabilecek ve bu kadar kompleks bir yapıyı yönetebilecek güçlü organizasyonlar tarafından desteklenmektedir. AIGN (Association of International Group of Nurseries), Better3Fruits, CIV (Consorzio Italiano Vivaisti), IFO, (International Fruit Obtention), Inova, Kiku Ltd, Prevar ${ }^{\mathrm{TM}}$, Varicom (Variety Commercialization and Communication) dünyada bu alanda önemli organizasyonlar arasindadir.

Yukarıda belirtilen başarılı örneklere rağmen kulüp çeşitler zaman zaman tartışılan ve tepki çeken bir yaklaşımdır. Nihayetinde bazı üreticiler bundan iyi bir gelir elde ederken bazıları ciddi kayıplar yaşayabilmektedir. Kulüp çeşitlerde üretici veya pazarlamacı için en büyük risk, doğru markanın/çeşidin seçiminde yaşanmaktadır (Luby ve Bedford 2015). Nitekim markalar özel koruma için ekstra maliyet gerektirmektedir. Dolayısıyla her bir çeşidin ona yapılan yüksek yatırımı karşılaması beklenilmektedir. Çeşit sahibi için, en büyük risk ise doğru üretici/pazarlamacı ortakların seçimidir (Luby ve Bedford 2015; Clark ve ark. 2012). Ortakların meyveyi üretmek, paketlemek ve pazara sunmak için yeterli fiziki imkânlara sahip olması gerekmektedir. Ayrıca, sürekli yüksek kalitede meyve üretebilmek için iyi bir bahçe yönetimi kabiliyetine sahip olmaları gerekmektedir. Özellikle talebi aşan bir durum, fiyatın düşmesine neden olacağı için üretim hacminin doğru planlanması büyük bir endişe kaynağıdır (Anonim 2015). Üreticinin, pazarlamacının ve çeşit sahibinin olumsuz etkilenmemesi için gereken bahçe ölçeğine pazarlamadan çok daha önce karar verilmesi gerekmektedir. 
Sektörde çok sayıda kulüp çeşidi olmasının birbirleriyle rekabet etmelerine neden olduğu ve dolayısıyla fiyatları kontrol etmede ciddi zorluklar yaşandığı yönünde görüşler de mevcuttur. Nitekim kulüp çeşitlerle ilgili olarak hala birçok insan yatırımların geri dönemeyeceğinden yada aşırı üretimden kaynaklanabilecek denetimsizlikten ötürü tereddüt etmektedir (Wilton 2017; Legun 2015; Anonim 2015; Luby ve Bedford 2015; Clark ve ark. 2012). $\mathrm{Bu}$ nedenle çeşide ait ön değerlendirmelerin çok iyi yapılması gerekmektedir. Dünyada bu konuda oldukça başarılı bağımsız değerlendirme programları yürütülmektedir. Örneğin Avustralya'da Australian Pome Fruit Improvement Program (APFIP) kapsamında yumuşak çekirdekli meyvelerin yoğun olarak üretildiği 12 bölgede çeşit değerlendirmeleri yapılmaktadır (Anonim 2017).

APFIP programında çeşitlerin farklı ekolojilerde test edilmesi hedeflenmiştir. Böylelikle çeşit sahiplerine farklı bölgelerden elde edilen veriler sunulmaktadır. Ayrıca çeşitlerin pazarlama programları ve hedef pazarların stratejik olarak planlanmasına yardımcı olunmaktadır. Her bölgede bir değerlendirme ekibi ve bir veri toplayıcı bulunmaktadır. Elde edilen veriler ise bir merkezde toplanmaktadır. Değerlendirme bölgeleri çalışan ekip hariç diğer kişilerce çok bilinmemektedir. Çeşitler isimsiz kodlu olarak değerlendirilmekte böylece bağımsızlık ve güvenilirlik açısından risk taşımamaktadır. Bu durum markanın veya bitki ıslahçı haklarının korunmasını da sağlamaktadır. Bu bağımsız değerlendirme programının sağladığı en önemli fayda ise yetiştiricilere doğru ve tarafsız değerlendirme imkanı sunmasıdır (Anonim 2017). Dolayısıyla böyle bir değerlendirme çeşitlere olan itibarı oldukça arttırmaktadır.

Gelinen noktada dünyada her gün birçok yeni çeşit ticarileşmek için sırada beklemektedir. Dolayısıyla çeşit yönetiminde dünyadaki ticari realitenin iyi anlaşılması önemlidir. Küresel bir elma markası oluşturabilmek için, mümkün olduğunca çok sayıda üreticiye ve dünya çapındaki ortaklara ihtiyaç duyulmaktadır (Wilton 2017; Legun 2015; Anonim 2015; Luby ve Bedford 2015). Dolayısıyla global düzeyde bir yönetim ve uluslararası işbirlikleri yeni çeşitlerin başarısında büyük önem taşımaktadır. Ayrıca çeşit yönetiminde her çeşidin kendi risk ve avantaj seviyesi iyi analiz edilmeli ve kapasitesinin detaylı bir değerlendirmesi yapılmalıdır. Bu kapsamlı kapasite değerlendirmeleri; çeşitlerin nereden geldiği, nasıl değerlendirildiği, her bir çeşidin rantabilitesi, her yıl yeni tesis edilen bahçe yüzdesi, eğer gerekirse ne kadar daha bahçe tesis edilebileceği, ambalajlama ve depolama kapasitesi, mevcut anlaşmalar ve yeni anlaşmalara yaklaşım, pazarlama stratejileri, pazarlara konum olarak yakınlık gibi birçok durum değerlendirmelerini içermelidir (Langford 2008). Ancak buradaki anahtar bileşeni çeşidin ömrü oluşturmaktadır ve dünyada temel kriter 50 yıl ve üstü olarak kabul edilmektedir.

Yukarıdaki bilgilerden de anlaşılacağı üzere 1slah programları için ticarileştirme ve pazarlama seçeneklerindeki ilerlemeler oldukça heyecan vericidir. Ancak bu gelişmeler aynı zamanda caydırıcı da olabilmektedir. Meyve endüstrisinde giderek artan rekabet yoğunluğuyla her yeni çeşidin potansiyel değerini alması ve koruması zorlaşmaktadır. Bu açıdan ıslah programları yeni bir döneme girmiş durumdadır. Küresel sorunları göz önünde tutarak etkin ve verimli ticarileştirme planlarına hızla uyum sağlamak durumundadırlar.

\section{Sonuç}

Yeni çeşitlerin başarısında farklılık oluşturan bir noktaya sahip olmaları çok önemlidir. Meyve ıslahçılarının çok sayıda 1slah programını incelemesi ve pazardaki zaman, tat ve lezzet gibi özellikler açısından boşlukların nerede olduğu konusunda fikir sahibi olması önemlilik arz etmektedir. Günümüzdeki meyve üretimini, pazarlamasını ve tüketimini etkileyen temel sorunları çok iyi analiz etmelidirler. Bununla birlikte şu anda geliştirilen çeşitlerin en az on yıl daha piyasada önemli olmayacağı dikkate alınırsa geleceğe dair sorunlar için de bir farkındalık oluşturmak zorundadırlar. Örneğin mevsime göre ekstrem sıcaklıklar ve ani su baskınları gibi çevresel kaygılar bütün dünyada giderek daha da önemli hale gelmektedir. Nitekim iklim değişikliğiyle ilgili zorluklarla baş etmede, yeni veya yerleşmiş hastalık ve zararlılarla mücadelede genetik çeşitliliğin önemi kesinlikle tartışılamaz duruma gelmiştir. Bu nedenle ıslahçıların çalışmalarını planlarken çevre kirliliği, sürdürülebilir tarım, biyoçeşitlilik ve küresel ısınma gibi birçok konuyu dikkate almaları gerekmektedir.

Dünyada çeşit tanıtımı ve yönetimi son yıllarda oldukça değişmiştir. Meyvecilik sektöründe değişim türlere bağlı olarak çok yavaş olmasına rağmen, bu durum giderek aşılmaktadır. Nitekim gelinen noktada yeni çeşitlerin yönetiminde küresel yönetim ve markalaşma kaçınılmazdır. Bölgesel bakış açıları bırakılarak altyapı ve koordinasyon olası riskleri hafifletmek için global düzeyde yapılmak zorundadır. Çünkü yeni çeşitlerin başarısı için mutlaka etkin bir pazarlama kampanyası, çok güçlü bir işbirliği ve desteğe ihtiyaç duyulmaktadır. Büyük üreticiler, toptancılar ve pazarlamacıların bir arada bulunduğu geniş üretim alanları başarı şansını arttırdı ̆̆ı için büyük avantaja sahiptirler. Türkiye gibi birçok ülkenin üretici özellikleri bu açıdan henüz çok uygun olmasa da önümüzdeki yıllarda elde edilen ürünlerin değerinin yükseltilebilmesi adına koşulların yeniden gözden geçirilmesi gerekebilir. 
Meyve ürünlerinin pazarlama ve ticarileşmesinde kulüp çeşitler, kapalı devre pazar sistemi gibi pazarlama modelleri çok yaygın hale gelmiştir ve elma endüstrisinin gidiş biçimi olarak düşünülmektedir. Çeşitleri korumada ve yüksek kar elde etmede şu an için en iyi yol olarak görülse de sistemlerin karmaşıklaşması birçok hataya yol açmakta ve bu durumda sistemler planlandığı gibi çalışmamaktadır. Bu noktada üreticilere sağlanan faydanın çok açık ve net olması gerekmektedir. Çeşit hakları ve onları korumaya yönelik faaliyetler birçok ülkede halen tam olarak şekillenmiş değildir. Islahçı haklarının türler bazında kuvvetlendirilmesi ve yenilikçi stratejilere uyumlu hale getirilmesi özellikle heterojen bir bitkisel üretime sahip ülkeler açısından çok önemlidir. Ayrıca mevcut pazarlama stratejisine alternatif olarak yeni pazarlama ağlarının geliştirilmesi, yeni çeşitlerin ıslahı ve ticaretinin yaygınlaştırılmasına yardımcı olabilir. Özellikle yerli ve bazı bölgesel üreticilere özel haklar ve istisnalar sunulması bu açıdan iyi bir yaklaşım olarak görülmektedir. Diğer taraftan çeşit sahipleri, potansiyel ihlalleri belirleyebilmek için sektörü daima gözetim altında tutmak durumundadırlar. Olası hak ihlallerine karşı koyabilmek için de mutlaka hukuki danışmanlığa ihtiyaç duyulmaktadır.

Sonuç olarak bu çalışmada özetlenen bilgilerin, elma ıslah çalışmalarında etkinliği ve bilinci arttırarak risklerin dengelenmesinde faydalı olabileceği ve diğer birçok bahçe bitkileri ıslah programlarına uygun yol gösterici nitelik taşıdı̆̆ı öngörülmektedir.

\section{Kaynaklar}

Anonim (2011). Developing future apple varieties - unit plan https://www.sciencelearn.org.nz/resources/882developing-future-apple-varieties-unit-plan (Erişim tarihi: 05.12.2017).

Anonim (2015). Assessment of B.C. apple \& sweet cherry varieties. A report by Globalwise, Inc. \& Belrose Inc. for British Columbia Ministry of Agriculture.

Anonim (2017). Australian pome fruit improvement program (APFIP). http://apal.org.au/industry-info/apfip/ (Erişim tarihi: 05.12.2017).

Atay A N, Atay E, Koyuncu F (2010). Dünya elma 1slah programlarına genel bir bakış. Bahçe, 39 (1): 31-44.

Atay A N, Atay E, Özongun Ş, Seymen T (2016a). Yeni ümitvar elma genotiplerinde muhafaza süresince meyve kalitesindeki değişimler. International Academic Research Congress: 804-810. November 3-5, 2016, Antalya.

Atay, A N, Özongun Ş, Seymen T, Bayav A, Atay E (2016b). Variability and heritability of floral development in apple full-sib offsprings. Genetika, 48 (1): 383-394, doi: 10.2298/GENSR1601383A.

Atay A N, Atay E, Lauri P E, Kunter B, Kantoğlu K Y (2018). Phenotyping gamma-ray-induced mutant population of 'Amasya' apple for architectural traits, precocity, floral phenology and fruit characteristics. Scientia Horticulturae 233: 195-203, doi: 10.1016/j.scienta.2018.01.003.

Brown S K, Maloney K E (2009). Making sense of new apple varieties, trademarks and clubs: current status. NY Fruit Quarterly 17(3): 9-12.

Brown S K, Maloney K E (2013). An update on apple cultivars, brands and club-marketing. NY Fruit Quarterly 21(1): 3-10.

Brown S K, Maloney KE (2015). Apple breeding, genetics and genomics. NY Fruit Quarterly 23(3): 5-8.

Byrne D H (2012). Trends in fruit breeding. In: Badenes M L, Byrne D H (eds), Fruit breeding. Handbook of plant breeding. Springer, US. p.3-36, doi:10.1007/978-1-4419-0763-9_1.

Clark J R, Jondle R (2008). Intellectual property rights for fruit crops. In: Hancock J F (ed), Temperate fruit crop breeding. Springer, Netherlands. p. 439-455, doi:10.1007/978-1-4020-6907-9_14.

Clark J R, Aust A B, Jondle R, (2012). Intellectual property protection and marketing of new fruit cultivars. Badenes M L, Byrne D H (eds), Fruit Breeding, Handbook of Plant Breeding 8, 69-96. Springer, DOI 10.1007/978-1-4419-0763-9_3.

Cripps J E L, Richards L A, Mairata A M (1993). ‘Pink Lady’ apple. HortScience 28:1057.

El-Ramady H R, Domokos-Szabolcsy É, Abdalla N A, Taha H S, Fári M (2015). Postharvest management of fruits and vegetables storage. Sustainable Agriculture Reviews 15: 65-152, Springer. DOI 10.1007/9783-319-09132-7_2.

Evans K (2013). Apple breeding in the Pacific Northwest. Acta Horticulturae 976: 75-78. DOI: 10.17660/ActaHortic.2013.976.6.

Hancock J F, Luby J J, Brown S K, Lobos G A (2008). Apples. In: Hancock J F(ed), Temperate fruit crop breeding: Germplasm to Genomics. Springer, Netherlands. p. 1-37. doi:10.1007/978- 1-4020-6907-9.

Heisey P W, Srinivasan C S, Thirtle C (2001) Public sector plant breeding in a privatizing world. Resource Economics Division, Economic Research Service, U. S. Department of Agriculture, Agriculture Information Bulletin No. 72.

Jondle R J, Hill K K, Sanny T (2015). Current legal issues in intellectual property rights and protection for crop plants. Crop Sci. 55: 2496-2503. doi:10.2135/cropsci2014.10.0693. 
Kumar S, Volz R K, Chagné D, Gardiner S (2014). Breeding for apple (Malus $\times$ domestica Borkh.) fruit quality traits in the genomics era. In: Tuberosa R, Graner A, Frison E (eds), Genomics of plant genetic resources.Springer, Netherlands. p. 387-416. doi:10.1007/978-94-007-7575-6_16.

Langford G (2008). What are you prepared to invest in new varieties? IFTA Conference Visalia, California. USA

Legun K A (2015). Club apples: a biology of markets built on the social life of variety, Economy and Society, 44:2, 293-315, DOI:10.1080/03085147.2015.1013743.

Lespinasse Y (2009.) Review of pome fruit breeding in Europe: Which strategies for the near future? Acta Hort. 814, 865-871.

Luby J (2011). Challenges and opportunities of breeding for consumer preferences in apple and grape. www.appliedplantsciences.umn.edu/prod/.../cfans_content_324270.pdf (Erişim tarihi: 10.05. 2012).

Luby J J, Bedford D S (2015). Cultivars as consumer brands: Trends in protecting and commercializing apple cultivars via intellectual property rights Crop Sci. 55: 2504-2510. doi: 10.2135/cropsci2014.10.0684.

Macduff J, Macduff C (2016). A new apple breeding programme in the Ystwyth Valley, West Wales. https://www.yvapplebreeders.com/ (Erişim tarihi: 05.12.2017).

O’Rourke D (2003). World production, trade, consumption and economic outlook for apples. In: Ferree D C, Warrington I J (eds.) Apples: botany, production, and uses. CABI publishing, CAB international, UK. p: $15-28$.

Özbek S (1971). Bağ-bahçe bitkilerinin 1slahı. Ankara Üniversitesi Ziraat Fakültesi Yayınları: 419, Ankara.

Pereira-Lorenzo S, Ramos-Cabrer A M, Fischer M (2009). Breeding apple (Malus Domestica Borkh). Jain S M, Priyadarshan P M (eds.), Breeding Plantation Tree Crops: Temperate Species, 33-81. Springer, DOI: 10.1007/978-0-387-71203-1_2.

Schmidt H, van de Weg W E (2005). Breeding. Tromp J, Webster A D, Wertheim S J (eds). Fundamentals of temperate zone tree fruit production. Leiden, The Netherlands, p. 136-155.

Volz R (2011). Breeding a new apple cultivar. https://www.sciencelearn.org.nz/resources/844-breeding-a-newapple-cultivar (Erişim tarihi: 05.12.2017)

Watkins C B (2003). Principles and practices of postharvest handling and stress. In: Ferree D C, Warrington (eds) Apples: botany, production, and uses. CABI publishing, CAB international, UK. p: 585-614.

Weber M (2017). Apple brands - factors of success. http://apal.org.au/wp-content/uploads/Apple-brands-factorsof-success-Michael-Weber.pdf (Erişim tarihi: 05.12.2017)

Webster A D (2005). Seed (generative/sexual) propagation of fruit trees and juvenility. Tromp J, Webster A D, Wertheim S J (eds.). Fundamentals of temperate zone tree fruit production. Leiden, The Netherlands, p. 84-92.

Wilton J (2017). Pros and cons of club varieties. Australian Fruitgrower, 11(4): 24-27. 